\title{
DIMENSÕES DA SUSTENTABILIDADE EM CURSOS DE LICENCIATURA A DISTÂNCIA DA ÁREA DE CIÊNCIAS NATURAIS: ESTUDO DOS PROJETOS PEDAGÓGICOS
}

\author{
Dionísia Fernanda Paixão Santos ${ }^{1}$ \\ Carlos Erick Brito de Sousa ${ }^{2}$ \\ Sannya Fernanda Nunes Rodrigues ${ }^{3}$
}

Resumo: O estudo realiza uma análise das dimensões da sustentabilidade nos projetos pedagógicos dos cursos de licenciatura a distância da área de Ciências Naturais da Universidade Federal do Maranhão. Para isso, optamos por uma abordagem qualitativa que abrange, enquanto procedimentos técnicos, análise documental. A linha metodológica adotada, para as análises dos projetos pedagógicos, foi a análise de conteúdo proposta por Bardin, complementada com o software IRAMUTEQ. A partir dos dados coletados, verificamos os cursos sinalizam princípios das dimensões da sustentabilidade para a formação de uma cidadania ambiental e para formação de sujeitos éticos e críticos, em contrapartida, os currículos dos cursos estão estruturados de forma linear o que dificulta o trabalho interdisciplinar. Deste modo, a interdisciplinaridade é vista como uma possibilidade de articulação entre as diferentes dimensões da sustentabilidade.

Palavras-chave: Sustentabilidade; Formação Docente; Educação a Distância.

Abstract: The study analyzes the dimensions of sustainability in the pedagogical projects of the bachelor's degree courses at a distance from the Natural Sciences area of the Universidade Federal do Maranhão. To this end, we opt for a qualitative approach that covers, as technical procedures, documentary analysis. The methodological line adopted for analyses of pedagogical projects was the content analysis proposed by Bardin, complemented with the IRAMUTEQ software. From the data collected, we find that all courses signal principles of sustainability dimensions for the formation of an environmental citizenship and for the training of ethical and critical subjects, on the other hand, course curricula are structured in a linear manner which makes interdisciplinary work difficult. Thus, interdisciplinarity is seen as a possibility of articulation between the different dimensions of sustainability.

Keywords: Sustainability; Teacher Training; Educating the Distance.

${ }^{1}$ Universidade Federal do Maranhão. E-mail: dionisiafernandaps.df@gmail.com

2 Universidade Federal do Maranhão. E-mail: carloserickbrito@gmail.com

${ }^{3}$ Universidade Federal do Maranhão. E-mail: rodriguessannya@gmail.com 


\section{Introdução}

O cenário da educação superior a distância no Brasil vive um período de grandes mudanças, principalmente pela ampla oferta de cursos on-line, de graduação e pós-graduação. Tal transformação é fruto, principalmente, de políticas públicas educacionais, a exemplo do Decreto no 5.800 de 8 de junho de 2006, que fomentou o Sistema Universidade Aberta do Brasil (UAB), cujo propósito é expandir o ensino superior público, nos municípios onde não há a oferta de formação superior ou não são suficientes para atender a demanda (BRASIL, 2020).

Em conformidade com os Referenciais de Qualidade para Educação Superior a Distância, não existe apenas um modelo de Educação a Distância $(\mathrm{EaD})$, visto que "[...] os programas podem apresentar diferentes desenhos e múltiplas combinações de linguagens e recursos educacionais e tecnológicos" (BRASIL, 2007, p. 7). Entretanto, um projeto pedagógico de curso superior a distância deve abordar, em seu processo de elaboração, as dimensões política para a formação cidadã e técnico-científica para o mundo do trabalho, sempre considerando a realidade local, em prol do desenvolvimento social, cultural e econômico da região.

Os fundamentos que justificam o presente estudo baseiam-se na percepção que a Terra deixou de ser um fenômeno unicamente geográfico tornando-se um fenômeno histórico. Portanto, carecemos de outros paradigmas, fundamentados em um olhar sustentável do planeta, uma vez que os formulados "[...] numa visão industrialista predatória, antropocêntrica e desenvolvimentista, estão se esgotando, não dando conta de explicar o momento presente e de responder às necessidades futuras" (GADOTTI, 2008, p. 73).

Nesse contexto, os projetos pedagógicos dos cursos (PPC) da área de Ciências da Natureza a distância (Biologia, Física e Química) podem expor princípios que sinalizam quais dimensões do conceito de sustentabilidade são adotadas para a formação destes profissionais.

Para tanto, Veiga $(2004$, p. 17) ressalta que "[...] a ideia do projeto pedagógico exige pensar o curso inteiro de forma orgânica, com vistas à construção de sua identidade". Assim, recomenda-se que as etapas da criação, implantação e execução dos PPC necessitam ser respeitadas e mediadas por informações, ações sólidas, específicas e inovadoras. Assim, este documento deve ser construído coletivamente, por todos os integrantes envolvidos com o processo educacional da instituição, assim, superando a ideia reducionista de simples documento regulador de um curso.

Mediante a isso, o presente artigo busca identificar quais dimensões do conceito de sustentabilidade são abordadas nos cursos de Licenciatura a distância em Ciências Biológicas, Física e Química, ofertados pela Universidade Federal do Maranhão (UFMA) por meio do convênio Ministério da Educação (MEC) e UAB. Empreende-se a análise documental dos PPC, como 
caminho metodológico a ser percorrido, aspirando identificar nos documentos, quais dimensões da sustentabilidade são abordadas nos cursos de formação de professores da área de Ciências da Natureza. No tocante ao tratamento dos dados, utilizou-se a análise de conteúdo proposta por Bardin (2016), complementada com o uso do software IRAMUTEQ. Desta forma espera-se que o presente estudo possa promover discussões sobre como as dimensões do conceito de sustentabilidade estão fundamentadas nos PPC da área de Ciências da Natureza e sua relevância para a formação docente.

\section{Sustentabilidade ambiental e suas dimensões}

Muitas definições de sustentabilidade são encontradas na literatura especializada. De tal modo que, ao longo dos anos, muitos autores vêm conceituando o termo a partir de diferentes linhas de pensamento, confrontando ideologias, concepções e valores.

No transcorrer deste tempo surgiram conceitos como: ecodesenvolvimento, desenvolvimento sustentável, Educação Ambiental, gestão ambiental, entre outros. No entanto, a falta de consenso na definição de sustentabilidade contrapõe duas grandes correntes de pensamento: a primeira, aproxima o conceito de sustentabilidade ao ecodesenvolvimento que, na compreensão de Sachs (1986), busca associar a preservação ambiental ao desenvolvimento social e econômico, isto é, consiste no crescimento econômico contínuo, baseando-se no uso racional de recursos naturais. E uma segunda corrente de pesquisa, que associa o conceito de sustentabilidade à área organizacional, abordando as nuances de um projeto político e social. Para essa corrente, faz-se necessário estabelecer indicadores de gestão que avaliem a sustentabilidade do desenvolvimento e o planejamento de políticas sustentáveis, tanto nas organizações públicas, privadas ou não governamentais (VAN BELLEN, 2005; DIAS, 2008).

Nesse contexto, a Conferência Mundial para o Meio Ambiente e Desenvolvimento (CMMAD), por meio do relatório "Nosso Futuro Comum" (também chamado de "Relatório Brundtland"), conceitua o desenvolvimento sustentável como "[...] aquele que atende às necessidades do presente, sem comprometer a possibilidade de as gerações futuras atenderem a suas próprias necessidades" (CMMAD, 1991, p. 46). O relatório sugere uma série de condições para desenvolvimento sustentável, sob o qual emerge o discurso dos três pilares do desenvolvimento sustentável: ambiental, econômico e social.

Segundo Romeiro (1991, p.149-150), as medidas compreendem três critérios, a saber: viabilidade econômica, prudência ecológica e desejabilidade social. Em síntese, estes critérios são definidos da seguinte forma: 
[...] viabilidade econômica: pressupõe a concepção de sistemas produtivos em que os custos de produção, medidos pela produtividade do trabalho obtida, sejam compatíveis com os níveis de bem-estar social considerados minimamente aceitáveis; Prudência ecológica: é uma exigência da necessária solidariedade diacrônica entre gerações, implicando o uso parcimonioso dos recursos naturais não-renováveis e sistemas de produção nos quais as grandes leis da natureza sejam respeitadas de modo a não transformar recursos renováveis em não-renováveis e; Desejabilidade social: pressupõe a solidariedade sincrônica entre classes sociais. Implica optar por padrões tecnológicos que, guardada a primeira condição, propiciem uma distribuição mais equitativa da renda gerada.

Nessa perspectiva, compreender o desenvolvimento sustentável é ampliar a área de alcance da interdisciplinaridade, dialogar com as diversas áreas do conhecimento e refletir sobre a condição humana como agente transformador da realidade. Para Leff (2011), a interdisciplinaridade do conhecimento deve ser orientada por um caráter holístico e integrador, para esclarecer a complexidade de sistemas socioambientais. Jara e Souto (2001) acentuam a necessidade de reflexões dos aspectos implícitos e subjetivos do desenvolvimento sustentável, destacando o fortalecimento do capital humano, social e cultural no processo de desenvolvimento sustentável.

Assim, as dimensões clássicas (ambiental, social e econômica) do conceito de sustentabilidade que surgem do discurso de desenvolvimento sustentável são integradas por outras dimensões: dimensão cultural, dimensão política (nacional e internacional), dimensão ética, dimensão espacial ou territorial e a dimensão jurídico-política. A seguir, é apresentada uma síntese das dimensões propostas por estudiosos do assunto, dentre os quais destacase (SACHS,1993; MENDES, 2009; BOFF, 2012; FREITAS, 2012; BRAUN; ROBL, 2015).

A dimensão cultural correspondente à evolução do processo de desenvolvimento cultural de cada região. Para Boff (2012, p. 50), a cultura favorece o cultivo das dimensões humanas como a religião, a arte, a ciência e outras expressões estéticas, assim como, abre espaço para "[...] uma forma de habitar a Terra que condiz melhor com a natureza humana que sempre produz cultura, também na área da produção e do consumo".

No que tange à dimensão política, esta exerce poder sobre a sociedade. Mendes (2009, p. 52) salienta que a dimensão política nacional se baseia na democracia e na apropriação dos direitos humanos, ou seja, permite o exercício da população e das organizações públicas e privadas na tomada de decisões políticas a respeito dos problemas ambientais de seus territórios, assim como suas soluções. A dimensão internacional abrange as necessidades ambientais em nível global, sendo fundamental a cooperação multilateral das 
nações para agir na "[...] prevenção da biodiversidade e da diversidade cultural; gestão do patrimônio global como herança da humanidade; cooperação científica e tecnológica internacional".

A dimensão ética da sustentabilidade empenha-se em proteger a heterogeneidade de visões de mundo e grupos sociais, dessa maneira, reconhece "[...] (a) a ligação de todos os seres, acima do antropocentrismo estrito, (b) o impacto retroalimentador das ações e das omissões, (c) a exigência da universalização concreta, tópico-sistemática do bem-estar" (FREITAS, 2012, p. 68-71).

Sobre a dimensão espacial, esta orienta a distribuição territorial e econômica de uma área rural-urbana, assim como, busca melhorias na área urbana "[...] superação das disparidades inter-regionais e elaboração de estratégias ambientalmente seguras para áreas ecologicamente frágeis a fim de garantir a conservação da biodiversidade e do ecodesenvolvimento" (MENDES, 2009, p. 52).

A dimensão jurídico-política, norteia a relação do campo constitucional com o direito do meio ambiente, asseverando que a sustentabilidade é um princípio constitucional, pois está prevista na Constituição da República Federativa do Brasil de 1988, em seu artigo 225: "[...] todos têm direito ao meio ambiente ecologicamente equilibrado, bem de uso comum do povo e essencial à sadia qualidade de vida, impondo-se ao Poder Público e à coletividade o dever de defendê-lo e preservá-lo para as presentes e futuras gerações" (BRASIL, 1988). Sendo assim, um princípio válido e um dever constitucional, "[...] devendo ser alterada a visão global do Direito, incorporando o desenvolvimento sustentável como condição normativa, para o qual todos os esforços jurídicos e políticos devem ser convergidos de forma obrigatória e vinculante" (BRAUN; ROBL, 2015, p.82).

Portanto, a sustentabilidade não está associada a um único ponto de vista em específico, mas assume um caráter multidimensional, aproximando-se dos conceitos de direitos sociais, de liberdade, de justiça social e de educação, que em conjunto estimulam transformações individuais necessárias para uma melhor qualidade de vida.

\section{Percurso Metodológico}

A presente pesquisa apresenta abordagem qualitativa, abordando procedimentos da análise documental. A pesquisa qualitativa é um processo que permite ao pesquisador refletir e analisar a realidade por meio da utilização de "[...] métodos e técnicas para a compreensão detalhada do objeto de estudo em seu contexto histórico e/ou segundo sua estruturação" (OLIVEIRA, 2007, p. 41). No que se refere à pesquisa documental, Oliveira (2007, p. 70 ) ressalta que "[...] o trabalho do pesquisador(a) requer uma análise mais cuidadosa, visto que os documentos não passaram antes por nenhum tratamento científico". Portanto, a análise documental permite ao pesquisador obter o máximo de 
informações, em documentos que não receberam nenhum tratamento analítico, isto é, fontes primárias.

Com o propósito de investigar quais dimensões da sustentabilidade estão presentes nos cursos da modalidade a distância da UFMA, estabeleceuse a análise documental dos PPC, como percurso metodológico do presente estudo. Os PPC foram obtidos junto ao órgão responsável pela gestão das ações de EaD da UFMA. Isto posto, foram coletados e analisados os PPC de licenciatura a distância em Ciências Biológicas, Física e Química.

Como referencial metodológico utilizou-se a análise de conteúdo proposta por Bardin, a qual consiste em uma técnica de análise das comunicações que objetiva por meio de procedimentos sistemáticos de "[...] descrição do conteúdo das mensagens indicadores (quantitativos ou não) que permitam a inferência de conhecimentos relativos às condições de produção/recepção (variáveis inferidas) dessas mensagens" (BARDIN, 2016, p. 48). Além disso, para complementar a análise dos dados, utilizou-se o software Interface de $R$ pour les Analyses Multidimensionnelles de Textes et de Questionnaires - IRAMUTEQ (2014), por este ser um programa que possibilita diferentes tipos de análise textuais desde a lexicografia básica "[...] até análises multivariadas (classificação hierárquica descendente, análises de similitude). Ele organiza a distribuição do vocabulário de forma facilmente compreensível e visualmente clara (análise de similitude e nuvem de palavras)" (CAMARGO; JUSTO, 2013, p. 515). Neste estudo optamos pelas análises de similitude e nuvem de palavras.

A análise de conteúdo incide em três fases: pré-análise; exploração do material; e tratamento dos resultados - inferências e interpretações. Na etapa da pré-análise, foi realizada a leitura flutuante dos PPC, que consiste em estabelecer um contato direto e intenso com os PPC, cujo objetivo foi formular objetivos e hipóteses e preparar o material para análise. Em seguida, prosseguiu-se para a etapa da exploração do material, que constitui na reorganização dos dados brutos em unidades (processo de codificação e categorização). Nesse percurso são especificadas as unidades de registro e unidade de contexto. Para os PPC, utilizou-se como unidades de registro 0 tema, a saber: "estrutura organizacional" e "estrutura curricular, como unidade de contexto, o parágrafo. A partir das similitudes das unidades de análises foi realizada a categorização dos PPC.

Cabe destacar que após o processo de categorização dos PPC os dados textuais foram submetidos ao software IRAMUTEQ por meio da análise de similitude e nuvem de palavras. A análise de similitude permite identificar as co-ocorrências entre as palavras e seu resultado é apresentado em formato de árvore, a partir do qual, a árvore graficamente gerada é composta por um núcleo central e deste surgem ramificações; o recurso nuvem de palavras agrupa as palavras em função da sua frequência, análise lexical mais simples, que possibilita rápida identificação das palavras-chave do corpus. As palavras geradas por este recurso são organizadas em tamanhos diferentes, ou seja, as 
palavras maiores detêm maior importância no corpus textual e estão mais próximas do centro e quanto mais distante e menor for seu tamanho, menor será o seu nível de hierarquização.

E por fim, a etapa do tratamento dos resultados obtidos e interpretação, fase em que o pesquisador apresenta inferências e realiza interpretações. Ressalta-se que em todo o processo de análise dos PPC, os documentos foram codificados como forma resguardar os cursos analisados. No presente estudo foi utilizado o código "PPC" para representar os projetos pedagógicos, acompanhados por números de 1 ao 3 .

\section{Uma leitura sobre a sustentabilidade nos projetos pedagógicos}

Por intermédio dos registros textuais dos PPC, buscou-se traçar elementos que viabilizassem a identificação das dimensões da sustentabilidade abordadas nos cursos analisados, bem como estas podem contribuir à educação para a sustentabilidade, verificando fatores como: objetivos do curso, perfil, competências e habilidades e ementário de cada disciplina, caracterizando assim, a amostra intencional do estudo desenvolvido.

A partir dos critérios definidos para a análise dos PPC, deu-se a construção de duas categorias: 1. Estrutura organizacional - tendo como indicadores - objetivos do curso e perfil do egresso e 2. Estrutura Curricular reunindo como indicadores - ementário e indicações bibliográficas. Para o entendimento das análises, os trechos retirados dos PPC serão trazidos ao longo das discussões.

Inicialmente, destaca-se que todos os projetos pedagógicos foram construídos sob a orientação única do órgão responsável pela gestão das ações de EaD na instituição de ensino superior analisada. Portanto, os três projetos pedagógicos investigados estão estruturados em duas partes, sendo estas: a primeira, dedicada a apresentar o curso e descrever a proposta da $\mathrm{EaD}$ na instituição - identificação do curso, justificativa, histórico da EaD na instituição e; a segunda, compete, exclusivamente ao projeto pedagógico de cada um dos cursos - descrição das equipes multidisciplinares, fundamentação, organização curricular, propostas metodológicas, processo de avaliação e núcleo docente estruturante.

No tocante à primeira categoria, estrutura organizacional, foi verificado que os cursos estão direcionados para a formação inicial e profissional de professores relacionadas ao ensino de suas respectivas áreas, assim como, para a formação pessoal. A seguir, alguns registros:

[...] promover a formação inicial de professores para a educação básica; desenvolver uma postura ética de atuação profissional que inclua a responsabilidade social e a compreensão crítica da ciência como fenômeno cultural e histórico; Compreender e avaliar criticamente os aspectos 
sociais, tecnológicos, ambientais, políticos e éticos relacionados às aplicações da Física na sociedade (PPC1).

[...] formar profissionais reflexivos, aptos a integrar o processo da educação básica de maneira responsável; Reconhecer a Química como uma construção humana e compreender os aspectos históricos de sua produção e suas relações com o contexto cultural, socioeconômico e político (PPC2).

[...] avaliar o impacto potencial ou real de novos conhecimentos, tecnologias, serviços e produtos resultantes da atividade profissional, considerando os aspectos éticos, sociais e epistemológicos; Exercer o Magistério na Educação Básica consciente de seu papel na formação de cidadãos críticos, inclusive na perspectiva socioambiental (PPC3).

Foi observado que há uma incidência regular das dimensões da sustentabilidade ambiental, social, cultural, política, ética, jurídico-política e econômica, sendo que a dimensão territorial ou espacial está ausente nos documentos. Por vezes, faz-se menção às expressões "equilíbrio populacional", "interações populacionais" e "estrutura populacional", mas não se deixa claro sobre qual equilíbrio, estrutura ou interação se faz referência. $A$ maior incidência foi da sustentabilidade social, o que evidencia a preocupação dos cursos em formar cidadãos aptos modificar a sociedade em que vivem por meio da educação. Portanto, os cursos destacam a compreensão de um projeto pedagógico preocupado com uma formação sólida e holística, mediante a um olhar crítico, ético e humanístico. A seguir, alguns trechos que desvelam este aspecto:

[...] contribui para a formação humanística (ética, sócioambiental e cidadã); formação científica (conhecimento de caráter teórico-científico); formação técnica (conhecimento de caráter técnico-profissional) (PPC1).

[...] capacidade crítica para analisar de maneira conveniente os seus próprios conhecimentos; assimilar os novos conhecimentos científicos e/ou educacionais e refletir sobre o comportamento ético que a sociedade espera de sua atuação e de suas relações com o contexto cultural, socioeconômico e político (PPC2).

[...] pautando sua conduta profissional por critérios humanísticos, compromisso com a cidadania e rigor científico, bem como por referenciais éticos legais (PPC3).

Os sistemas nacionais de educação surgiram como ato da constituição do estado-nação. Portanto, educar para um mundo possível exige dos educadores uma postura ético-eco-político-pedagógica de escuta do universo. Para tanto, é necessário reconhecer que as dimensões da sustentabilidade podem estar lado a lado ou entrelaçadas, para a compreensão da realidade e 
das problemáticas ambientais e humanas (GADOTTI, 2008; ANTUNES; NASCIMENTO; QUEIROZ, 2018).

De acordo com Silva e Carvalho (2017, p, 208) é primordial que os cursos de formação de professores a distância não esqueçam do seu compromisso social "[...] uma formação plena e totalizante a todos que passem por essa modalidade de ensino, o que se traduz entre outros aspectos, pela incorporação da dimensão ambiental em seus currículos formativos"

A matriz curricular dos cursos analisados segue a orientação das Diretrizes Curriculares das suas respectivas áreas, estando organizada em núcleos que contemplam conteúdos específicos, pedagógicos, instrumentais e modalidades educativas.

A abordagem das dimensões da sustentabilidade na ementa dos cursos investigados não é regular, isto é, as dimensões nas disciplinas estão distribuídas de forma heterogênea ao longo dos períodos (Quadro 1). Contudo, observa-se uma centralização das disciplinas entre o primeiro e terceiro período dos cursos de Química e Ciência Biológicas, quando os conteúdos pedagógicos são lecionados.

Quadro 1: Disciplinas que abordam uma ou mais dimensões da sustentabilidade

\begin{tabular}{|c|c|c|c|c|c|c|c|c|}
\hline Documentos & $\mathbf{1 ~ P}$ & $\mathbf{2} \mathbf{P}$ & $\mathbf{3} \mathbf{P}$ & $\mathbf{4} \mathbf{P}$ & $\mathbf{5} \mathbf{P}$ & $\mathbf{6} \mathbf{P}$ & $\mathbf{7} \mathbf{P}$ & $\mathbf{8} \mathbf{P}$ \\
\hline PPC1 & - & - & - & - & $1 \mathrm{D}$ & - & - & $1 \mathrm{D}$ \\
\hline PPC2 & $1 \mathrm{D}$ & $2 \mathrm{D}$ & $1 \mathrm{D}$ & - & - & - & - & $2 \mathrm{D}$ \\
\hline PPC3 & $1 \mathrm{D}$ & 2D & $1 \mathrm{D}$ & - & - & - & - & $2 \mathrm{D}$ \\
\hline
\end{tabular}

Legenda: P - período; D - disciplinas.

Fonte: Elaborado pelos autores(2021).

Portanto, essa desarticulação entre saberes específicos e saberes pedagógicos pode propiciar problemas na formação docente, tanto nos cursos de licenciatura a distância quanto nos presenciais. Além disso, os conhecimentos específicos não devem ser dissociados das questões sociais, culturais, políticas e econômicas.

[...] e não se diga que, se sou professor de biologia, não posso me alongar em considerações outras, que devo apenas ensinar biologia, como se o fenômeno vital pudesse ser compreendido fora da trama histórico-social, cultural e política (FREIRE, 1992, p. 78).

Não obstante, destaca-se que a formação da identidade profissional do aluno está estreitamente associada à organização curricular dos cursos, isto é, cursos que apresentam o perfil do aluno egresso direcionado a um fazer técnico-experimental, de certa maneira, se afastam em alguns momentos do fazer docente, atividade primeira do licenciando. Para Dimas, Novaes e Avelar (2021) falhas na estrutura curricular corroboram para que os docentes não 
apresentem competências necessárias para a melhor utilização da Educação Ambiental de forma interdisciplinar.

No programa das disciplinas, prepondera uma abordagem direta, isto é, o conceito de sustentabilidade é abordado ou corresponde ao termo sustentável nos conteúdos ou referências das disciplinas. Em tese, uma abordagem direta da sustentabilidade encontra-se associada às disciplinas que discutem as relações entre ambiente, sociedade e ciências humanas. No Quadro 2 é possível observar a caracterização das disciplinas que indicam diretamente pelo menos uma das dimensões do conceito de sustentabilidade em sua proposta pedagógica, conforme a descrição das ementas, referências básicas ou complementares.

\begin{tabular}{|c|c|c|c|c|c|c|c|c|c|c|c|}
\hline \multirow[b]{2}{*}{$\begin{array}{c}\text { Projeto } \\
\text { pedagógico }\end{array}$} & \multirow[b]{2}{*}{ Disciplinas } & \multicolumn{10}{|c|}{ Dimensões } \\
\hline & & AM & SC & EC & ET & PL & $\mathrm{CL}$ & JP & TR & RB & RC \\
\hline PPC1 & $\begin{array}{l}\text { Evolução dos } \\
\text { conceitos na } \\
\text { física }\end{array}$ & - & 1 & 1 & - & 1 & - & - & - & 2 & - \\
\hline PPC1 & $\begin{array}{c}\text { Física e Meio } \\
\text { Ambiente }\end{array}$ & 1 & 1 & 1 & 1 & 1 & 1 & 1 & - & 3 & - \\
\hline PPC1 & $\begin{array}{c}\text { Sociologia da } \\
\text { educação }\end{array}$ & - & 2 & - & 1 & 1 & 1 & - & - & - & - \\
\hline PPC2 & $\begin{array}{l}\text { História e } \\
\text { filosofia da } \\
\text { educação }\end{array}$ & 1 & 2 & 1 & 1 & 2 & 1 & - & - & 1 & 2 \\
\hline PPC2 & $\begin{array}{c}\text { Sociologia da } \\
\text { educação }\end{array}$ & - & 3 & - & 2 & 2 & 1 & - & - & 2 & 2 \\
\hline PPC2 & $\begin{array}{c}\text { História da } \\
\text { química }\end{array}$ & 1 & 1 & - & 1 & 1 & - & - & - & 1 & 1 \\
\hline PPC2 & $\begin{array}{c}\text { Política e } \\
\text { planejamento } \\
\text { educacional }\end{array}$ & - & 2 & 1 & 1 & 1 & - & - & - & 2 & 3 \\
\hline PPC2 & $\begin{array}{l}\text { Química } \\
\text { ambiental }\end{array}$ & 5 & 1 & 1 & 1 & 1 & - & 1 & - & 3 & 5 \\
\hline PPC2 & Biologia geral & 1 & - & - & - & - & - & - & - & 1 & 3 \\
\hline PPC3 & $\begin{array}{c}\text { Fundamentos } \\
\text { de Ecologia e } \\
\text { Evolução }\end{array}$ & 4 & - & - & - & - & - & - & - & 2 & 1 \\
\hline PPC3 & $\begin{array}{l}\text { Sociologia da } \\
\text { Educação }\end{array}$ & - & 2 & 1 & 2 & 1 & 1 & - & - & 2 & 1 \\
\hline PPC3 & $\begin{array}{c}\text { Política e } \\
\text { Planejamento } \\
\text { Educacional }\end{array}$ & - & 2 & 1 & 2 & 1 & - & - & - & 3 & 3 \\
\hline PPC3 & Ecologia & 8 & 2 & 1 & 2 & - & - & - & - & 4 & 3 \\
\hline PPC3 & $\begin{array}{l}\text { Biologia da } \\
\text { Conservação }\end{array}$ & 4 & 1 & - & - & - & - & - & - & 3 & 3 \\
\hline
\end{tabular}

Quadro 2: Disciplinas que apontam a presença das dimensões da sustentabilidade nos projetos pedagógicos.

Legenda:

AM - ambiental;

SC - social;

EC - econômica;

ET - ética;

CL - cultural;

PL política;

JP - jurídico-política;

TR - territorial;

RB - referência básica;

$\mathrm{RC}$ - referência complementar

(-) - ausência.

Fonte: Elaborado pelos autores (2021). 
Destaca-se, então, a disciplina do PPC1 intitulada "Física e Meio Ambiente", ofertada no oitavo semestre que aborda em sua ementa de componentes tópicos para discussões, tais como:

[...] fontes de energia. Energia e a questão ambiental. Equilíbrio térmico da Terra e efeito estufa, camada de ozônio e radiação cósmica. Poluição e impactos ambientais, água, ar e solo. Legislação ambiental e planejamento e gestão ambiental (PPC1).

Essa ementa de componentes, aponta as dimensões da sustentabilidade em cinco momentos (ambiental, social, econômica, ética, política e jurídicopolítica), assim como coaduna com três referências básicas, a exemplo dos trabalhos de André Trigueiro, Roger Heinrich; Merlin Kleinback e Célio Bergman. Destarte, pode-se observar a nuvem de palavras das ementas dos componentes dos PPC1, PPC2 e PPC3 que denotam mais representatividade nesse âmbito, como segue na Figura 1.

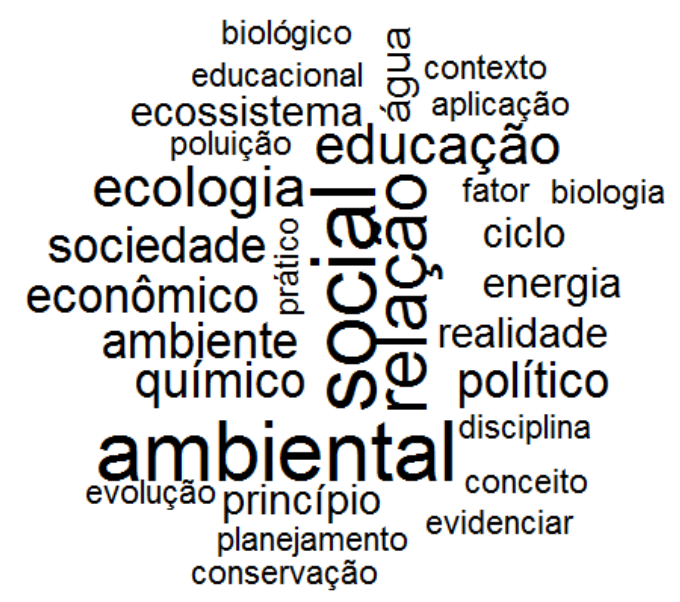

Figura 1: Nuvem de palavras específica das ementas dos PPC Fonte: Imagem elaborada a partir do software IRAMUTEQ(2021).

Termos como social, ambiental e relação tornam-se palavras primárias, pois destacam-se de modo expressivo, uma vez que há uma frequência maior de co-ocorrências desses termos nas ementas dos PPC. As demais expressões encontram-se relacionadas de forma secundária aos termos primários. Entretanto, a nuvem de palavras exprime as dimensões da sustentabilidade presentes nas relações ambientais e humanas.

As disciplinas "Química Ambiental" (PPC2) e "Ecologia" (PPC3), ambas do núcleo de formação específica dos professores abordam com frequência a dimensão ambiental da sustentabilidade em suas ementas. A seguir, os registros: 
[...] ecologia; Meio Ambiente; Química do meio ambiente; O ciclo da água; O ciclo do carbono; O ciclo do nitrogênio; Água e saúde. Doenças e problemas de poluição; Os tipos mais comuns de poluição química; critérios de qualidade da água; métodos de controle; critérios de qualidade do ar; efeitos dos poluentes sobre os seres vivos; estudo dos principais poluentes; fontes móveis e estacionárias; métodos de determinação; controle; Legislação ambiental (Lei Federal 9.795/1999, art. 11- Política Nacional de Educação Ambiental) (PPC2).

[...] aspectos sistêmicos do funcionamento da Biosfera. Natureza dos ecossistemas. Fluxo de energia nos ecossistemas. Ciclos bioquímicos e os ecossistemas. Biomas do Mundo. Ecossistemas do Maranhão. Conceitos, princípios e aplicações da Ecologia com especial referência à problemática ambiental. Processos evolutivos em populações e comunidades. Discussão de métodos de estudo em ecologia evolutiva. Recursos, condições, habitat e nicho. Fatores históricos. História de Vida. Dinâmica de populações e metapopulações. Interações populacionais. Comunidades: estrutura e padrões temporais e espaciais. Padrões de riqueza de espécies(PPC3).

Entende-se que, por serem cursos da área de Ciências da Natureza, fazse evidente o enfoque epistemológico no tratamento das questões ambientais contemplando os problemas socioambientais em uma perspectiva social e global. Para Gutiérrez e Prado (2000), a formação de uma cidadania ambiental é um elemento estratégico para a construção da democracia, pois a cidadania ambiental é planetária, cujo movimento ecológico local e global se conectam, tendo como exemplo "[...] a derrubada da floresta amazônica, ou de qualquer floresta do mundo, não é apenas um fato local. É um atentado contra a cidadania planetária" (GADOTTI, 2008, p. 31).

Portanto, há que ser evidenciado que a disciplina "Sociologia da Educação" tem contribuído para a fundamentação de diversas disciplinas que compõem o currículo dos cursos de licenciatura, visto que se trata de um componente curricular que possibilita aos futuros docentes, uma compreensão da realidade e dos problemas sociais.

[...] a "crise dos paradigmas" das ciências sociais e os estudos sobre educação: modelos microssociológicos e etnográficos. Abordagens weberianas em sociologia da educação (PPC1).

[...] compreender a relação entre a escola e o contexto social mais amplo, evidenciando os fatos sócio-político-econômicos determinantes da reprodução da realidade social, bem como as possibilidades de contribuir com a transformação dessa realidade (PPC2). 
[...] refletir sobre a função social da escola em promover a formação de um cidadão mais crítico, humanizado, participativo na constituição de uma sociedade mais justa e democrática(PPC3).

De acordo com Araújo e Pedrosa (2014, p. 306), a formação do cidadão conquista espaço cada vez mais na educação científica, ou seja, existe uma tendência das sociedades ocidentais "[...] na perspectiva de alteração do modo como é trabalhada a educação científica, passando-se a considerar o reconhecimento social e político do papel das ciências e das tecnologias". Uma compreensão crítica da realidade social, cultural, econômica e política contribui para uma formação de professores com um olhar que possa formar cidadãos a compreenderem e transformarem o ambiente onde vivem.

A Educação como prática social busca formar cidadãos para a vida em sociedade permitindo, assim, a compreensão da sociedade em todas as suas dimensões. Para Baudelot (1991, p. 30-31) o objetivo da disciplina "Sociologia, da Educação" é de ordem prática que trata-se de uma análise objetiva do sistema de ensino, sua história, suas funções, seus conteúdos e de seus ideais para obter dois resultados "[...] 1. Mobilizar os professores, infundindo ou dando-Ihes a fé (...) 2. Armar os professores de conhecimentos sobre o sistema de ensino, de forma que eles próprios possam contribuir para transformá-lo, com conhecimento de causa". Daí a importância de a disciplina ser lecionada em todos os níveis da educação.

Observou-se ainda que, a dimensão Jurídico-Política da sustentabilidade foi evidenciada apenas nas disciplinas "Física e Meio Ambiente (PPC1) e "Química Ambiental" (PPC2). Portanto, o currículo estruturado em disciplinas, ainda, dificulta o trabalho interdisciplinar. Para Fazenda (2002, p. 89) "[...] a estrutura linear em si já é uma forma de provocar a compartimentização do saber em conteúdos estanques". Logo, as dimensões da sustentabilidade devem ser estudadas em conjunto, a exemplo, a dimensão ambiental que aborda a temática preservação ambiental, se não for corretamente discutida pode gerar uma crise nas demais dimensões da sustentabilidade social, e o inverso também poderá ocorrer, pois "[...] a deterioração material do planeta é insustentável, mas a pobreza também é insustentável, a exclusão social também é insustentável, assim como a injustiça, a opressão, a escravidão e a dominação cultural e econômica" ( MAFRA, 2015, p. 555).

Em vista disso, dispor o direito e Dever Fundamental de proteção ao meio ambiente quer dizer que cada cidadão tem o direito a um ambiente sadio e equilibrado, mas também possui o dever de lutar, por meio de participações, a favor da preservação do habitat natural (MEDEIROS, 2004). Assim, a dimensão jurídico-pedagógica tem como uma das inquietações promover o desenvolvimento sustentável dos povos de maneira a preservar o meio ambiente equilibrado para as futuras gerações. 
No entanto, salienta-se que existem instrumentos legais no Brasil, entre os quais contidos na Lei no 9.795, de 27 de abril de 1999, que institui a Política Nacional de Educação Ambiental, destacando os princípios básicos da Educação Ambiental. Conforme o art. 4ํㅡㄹ da referida Lei,

[...] I - o enfoque humanista, holístico, democrático e participativo; II - a concepção do meio ambiente em sua totalidade, considerando a interdependência entre o meio natural, o socioeconômico e o cultural, sob o enfoque da sustentabilidade (BRASIL, 1999).

Depreende-se que o meio ambiente deixa de ser abordado como tema isolado e passa a ser assunto de todas as áreas do conhecimento, posto que a Educação Ambiental apresenta um caráter interdisciplinar, o que permite que cada ementa aborde a temática de acordo com sua realidade, compreendendo estas questões de modo abrangente, holístico e multidimensional.

\section{Considerações Finais}

O estudo analisou como as dimensões da sustentabilidade estão inseridas nos PPC dos cursos de Licenciatura a distância em Ciências Biológicas, Física e Química da UFMA. Nesse percurso, verificou-se que todos os PPC dos cursos abordam a dimensão social da sustentabilidade, sob uma perspectiva ambiental, sociopolítica, econômica e humana, buscando a formação de sujeitos éticos e críticos, o que vai além da educação teóricoexperiencial. No entanto, percebe-se a ausência da dimensão territorial ou espacial nos PPC analisados, sendo fator que precisa ser levado em consideração na reformulação destes documentos.

Portanto, a inserção das dimensões da sustentabilidade nos PPC permite compreender a visão de mundo e de sociedade que uma instituição de ensino apoia, assim como, sinalizam as interpretações de sustentabilidade que o profissional terá contato ao longo do processo formativo, empenhando-se em superar a formação técnica para contemplar uma formação cidadã.

Não obstante, é essencial que os cursos acrescentem, em suas propostas, referenciais teóricos direcionados à educação para a sustentabilidade respondendo as novas demandas sociais do desenvolvimento sustentável, exigindo maior interdisciplinaridade. Deste modo, mesmo que essa dificuldade seja reconhecida, o trabalho interdisciplinar tem sido visto como uma possibilidade de articulação dos diferentes campos do saber. Portanto, é preciso desenvolver um trabalho de formação docente interdisciplinar para que transforme e coloque em prática tal mudança. 


\section{Referências}

ARAÚJO, M. F. F; PEDROSA, M. A. Ensinar ciências na perspectiva da sustentabilidade: barreiras e dificuldades reveladas por professores de biologia em formação. Educar em Revista, Curitiba, n. 52, 2014.

ANTUNES, J; NASCIMENTO, V.S; QUEIROZ, Z. F. Educação para sustentabilidade, interdisciplinaridade e as contribuições da mediação para a construção coletiva do conhecimento. Rev. Eletrônica Mestr. Educ. Ambient, Rio Grande, v. 35, n. 1, 2018.

BARDIN, L. Análise de Conteúdo. São Paulo: Edições 70, 2016.

BAUDELOT, C. A Sociologia da Educação: para quê?. Teoria e Educação, n.3, p. 29-42, 1991.

BOFF, L. Sustentabilidade: o que é-o que não é. Petrópolis, RJ: Vozes, 2012.

BRASIL. Constituição da República Federativa do Brasil. 1988. Disponível em: <http://www.planalto.gov.br/ccivil 03/constituicao/constituicao.htm>.

Acesso em: 12 jan. 2020.

BRASIL. Ministério da Educação. Referenciais de qualidade para educação superior a distância. $2007 . \quad$ Disponível em: $<$ http://portal.mec.gov.br/seed/arquivos/pdf/legislacao/refead1.pdf>. Acesso em: 27 jan. 2020.

BRASIL. Lei 9.795, de 27 de abril de 1999. Institui a Política Nacional de Educação Ambiental. Diário Oficial da União, Brasília, seção 1, p. 1-4, abr. 1999. Disponível em: <http://www.planalto.gov.br/ccivil 03/leis/l9795.htm>. Acesso em: 28 jan. 2020.

BRASIL. Ministério da Educação. Coordenação de Aperfeiçoamento de Pessoal de Nível Superior - CAPES. Universidade Aberta do Brasil. 2019. Disponível em: <http://www.capes.gov.br/uab/o-que-e-uab>. Acesso em: 27 jan. 2020.

BRAUN, D. M. R; ROBL, R. O ICMS ecológico como instrumento auxiliar para o alcance da sustentabilidade. In: SOUZA, M. C. S. A; ARMADA, C. A. Sustentabilidade, meio ambiente e sociedade: reflexões e perspectivas. Umuarama: Universidade Paranaense, 2015.

CAMARGO, V. B; JUSTO, M. A. IRAMUTEQ: Um Software Gratuito para Análise de Dados Textuais. Temas em Psicologia, Ribeirão Preto, v. 21, n. 2, 513-518, 2013.

CMMAD - Comissão Mundial sobre Meio Ambiente e Desenvolvimento. Nosso futuro comum. 2. ed. Rio de Janeiro: Editora FGV, 1991.

DIAS, R. Gestão Ambiental: responsabilidade social e sustentabilidade. São Paulo: Atlas, 2008.

DIMAS, M, S. NOVAES, A, M, P. AVELAR, K, E, S. O ensino da Educação Ambiental: desafios e perspectivas. Revista Brasileira de Educação Ambiental, São Paulo, v. 16, n. 2: 501-512, 2021. 
FAZENDA, I. C. A. Integração e interdisciplinaridade no ensino brasileiro: Efetividade ou ideologia. São Paulo: Loyola, 2002.

FREIRE, P. Pedagogia da Esperança: um reencontro com a Pedagogia do Oprimido. Rio de Janeiro: Paz e Terra, 1992.

FREITAS, J. Sustentabilidade: direito ao futuro. 2. ed. Belo Horizonte, MG: Fórum, 2012.

GADOTTI, M. Educar para a sustentabilidade: uma contribuição à década da educação para o desenvolvimento sustentável. 2008. São Paulo: Instituto Paulo Freire, 2008.

GUTIÉRREZ, F. PRADO. Ecopedagogia e cidadania planetária. Guia da Escola Cidadã v. 3. São Paulo: Cortez, 2000.

IRAMUTEQ. Interface do $\mathbf{R}$ para Análises Multidimensionais de Texto e Questionários. Software gratuito construído com software livre. Versão 0.7 alpha 2. Laboratório LERASS. 2014. Disponível em: <http://www.iramuteq.org/>. Acesso em: 27 jan. 2020.

JARA, J.C; SOUTO, M.V.M. As dimensões intangíveis do desenvolvimento local. Brasília: IICA, 2001.

LEFF, E. Saber Ambiental: sustentabilidade, racionalidade, complexidade e poder. 8 ed. Petrópolis: Vozes, 2011.

MEDEIROS, F.L.F. Meio ambiente: direito e dever fundamental. Porto Alegre: Livraria do Advogado, 2004.

MENDES, J.M.G. Dimensões da Sustentabilidade. Revista das Faculdades Integradas Santa Cruz de Curitiba, Curitiba, v. 7, n. 2, p. 49-59, 2009.

OLIVEIRA, M.M. Como fazer pesquisa qualitativa. Petrópolis: Vozes, 2007.

ROMEIRO, A.R. Desenvolvimento econômico e a questão ambiental: algumas considerações. Revista de Análise Econômica, Porto Alegre, v. 9, n.16, p.141-152, 1991.

SACHS, I. Ecodesenvolvimento, crescer sem destruir. São Paulo: Vértice, 1986.

SACHS, I. Estratégias de transição para o século XXI: desenvolvimento e meio ambiente. São Paulo: Studio Nobel, 1993.

SILVA, J,S. CARVALHO, M.E.S. A Educação Ambiental na educação a distância: contribuições à prática pedagógica do curso de formação de professores em geografia da universidade federal de Sergipe. Revista Brasileira de Educação Ambiental, São Paulo, v. 12, n. 2, p. 199-208, 2017.

VAN BELLEN, H. M. Indicadores de sustentabilidade: uma análise comparativa. Rio de Janeiro: Editora FGV, 2005.

VEIGA, I. P. A. Educação superior: projeto político-pedagógico. Campinas: Papirus,2004. 